\title{
Postural control and contingent negative variation during transient floor translation while standing with the ankle fixed
}

\author{
Vitalii Lytnev ${ }^{1}$, Katsuo Fujiwara ${ }^{2 *}$, Naoe Kiyota ${ }^{3}$, Mariko Irei $^{4}$, Hiroshi Toyama ${ }^{2}$ and Chie Yaguchi $^{5}$
}

\begin{abstract}
Background: Adaptation changes in postural muscle activity and anticipatory attention were investigated with the ankle joint fixed to change postural control strategies during transient floor translation.

Methods: For 15 healthy young adults, 40 transient floor translations (S2) in the anterior direction were applied $2 \mathrm{~s}$ after an auditory warning signal (S1), under conditions with or without fixation of the ankle. Activity of the frontal postural muscles (tibialis anterior (TA), rectus femoris (RF), rectus abdominis) and contingent negative variation (CNV, brain potential) were analyzed for 20 trials each of the early and latter halves under each fixation condition.

Results: With fixation, peak amplitude of muscle activity after S2 was significantly decreased in TA and increased in RF. These muscles showed marked adaptive decreases. The early component of CNV reduced with adaptation, particularly under fixation condition. Only in RF, background activity increased just before $\mathrm{S} 2$, with adaptation under fixation. A significant correlation was found between timings of CNV peak and RF activation just before S2 only after adaptation under fixation.

Conclusion: These results suggest that the main activation muscle changes from TA to RF with fixation. Under such condition, attention would be focused on the knee with adaptation, and the need for heightening attention in the early stage may have declined. Correspondingly, the timing to heighten stiffness of the RF became later, and attention would have been paid to RF activation just before S2.
\end{abstract}

Keywords: Floor translation, Contingent negative variation, Postural control, Joint fixation

\section{Background}

The standing posture is a human characteristic; however, its control dynamics is highly complicated. Many researchers have investigated postural responses to external perturbations while standing to clarify the dynamic characteristics of the postural control system [1-4]. Transient forward floor translation can be applied to cause backward disturbance $[5,6]$. The main joint for postural control with floor translation has been reported as the ankle [3]. However, many degrees of freedom in joints and muscles are available to facilitate the maintenance of upright standing [7]. Postural control strategies in response to external disturbances could thus vary between both

\footnotetext{
* Correspondence: fujikatu@kanazawa-gu.ac.jp

${ }^{2}$ Department of Sports and Health, Kanazawa Gakuin University, 10

Sue-machi, Kanazawa 920-1392, Japan

Full list of author information is available at the end of the article
}

individuals and situations [3, 8]. If the main joint (ankle) for postural control cannot be used due to reasons such as aging or impairment, postural control strategies would change considerably [9-12]. However, few studies have investigated changes in postural control strategy during backward disturbance or the process of adaptation to a new strategy in detail $[13,14]$.

Joint fixation, which decreases the degrees of freedom, is one method for changing the postural control strategy. Fujiwara et al. [15] fixed all joints of the leg and trunk above the ankle during transient floor translation. Although postural control was focused on the triceps surae, fixation of joints other than the ankle could not change the postural control strategy largely because the ankle was mainly used also in postural control to the transient floor translation without the fixation. On the other hand, fixation of the ankle will allow us to investigate 
changes in the postural control strategy and adaptation processes. During transient forward floor translation, the tibialis anterior (TA) activates mainly against the backward postural disturbance, pivoting at the ankle $[3,16]$. If the ankle joint were fixed, backward disturbance would occur around the knee joint and the main activation muscle would thus change to the rectus femoris (RF). With repetition of postural disturbances during floor oscillation, as a comparatively novel task, activation of postural muscles would adaptively decrease [17]. Therefore, according to postural adaptation with ankle joint fixation, RF activation would decrease.

We have previously investigated the relationship between postural muscle activities and contingent negative variation $(\mathrm{CNV})$, obtained by averaging the electroencephalogram (EEG) recorded between warning (S1) and imperative (S2) stimuli $[15,16,18-21]$. The late component of $\mathrm{CNV}$ reflects the motor preparation process and anticipatory attention directed to S2 [22, 23]. Late $\mathrm{CNV}$ shows a peak just before S2, which has been suggested to correspond to a peak of anticipatory attention and/or onset of attentional shift to objects other than S2, such as sensory information and output of motor commands [20, 24]. When S1 was a simple warning and S2 was an imperative stimulus of finger response or arm movement, the negative potential of late $\mathrm{CNV}$ seemed to gradually increase until S2 onset [21, 25]. On the other hand, when $\mathrm{S} 2$ was a transient floor translation, the negative potential seemed to increase at a relatively early stage of the S1-S2 period $[16,26]$. When the response to S2 was determined by $\mathrm{S} 1$ or trial was considerably repeated, the negative potential of early $\mathrm{CNV}$ was small $[27,28]$. These findings suggest that when early preparation for the response to $\mathrm{S} 2$ is allowed and needed, CNV would increase negatively in the early period of S1-S2. In the floor translation task, subjects should direct their attention to and prepare for S2, since a rapid, large disturbance is applied just after S2. However, if the necessity for anticipatory attention and postural preparation in the early period is reduced by postural adaptation under ankle joint fixation, the negative potential in the early period of S1-S2 will be decreased.

In a floor translation task with predictable timing of the disturbance (i.e., S1-S2 paradigm), continuous or transient activities in the main postural muscles have been observed prior to $\mathrm{S} 2$, relating to increasing muscle stiffness against the disturbance or control of standing position to moderate the influence of disturbance, respectively $[15,16,20]$. These would represent the strategies of postural preparation for the disturbance. In forward floor translation, background activity of TA was continuously increased before S2 [16]. Therefore, when forward translation is applied with the ankle joint fixed, increased muscle stiffness would be observed in the RF.
Then, if the necessity for postural preparation is decreased with postural adaptation under ankle fixation, the increase in the time to muscle stiffness is expected to be close to S2 onset. Such a change in RF activity with adaptation may correspond to the change in CNV with adaptation.

In addition, the start time of these muscle activations for postural preparation is reportedly earlier than the peak time for late $\mathrm{CNV}$, with a high correlation between these times $[16,20]$. After postural adaptation to the backward floor translation with fixation of the knee, hip, and trunk, a high correlation with CNV peak time was found for the start time of triceps surae activation [15]. These findings suggest that attention would be directed to the sensory information processing related to the activity in the main muscle preceding the disturbance. With the advance of postural adaptation in ankle joint fixation, attention will be directed primarily to RF, the main muscle for postural control following the disturbance, and consequently, a high correlation will be observed between $\mathrm{CNV}$ peak time and start time of RF activation before S2. However, the level of correlation would be lower than that with fixation of the upper part above the ankle, because of the greater degrees of freedom.

In the present study, the ankle joint was fixed to change the postural control strategy, and adaptation changes in postural muscle activation and anticipatory attention to forward floor translation were investigated. Working hypotheses were as follows. First, with ankle joint fixation, the focus of postural control would change from TA to $\mathrm{RF}$, and RF activation would then decrease with postural adaptation. Second, with postural adaptation under ankle joint fixation, negative potential in the early period of $\mathrm{S} 1-\mathrm{S} 2$ would be decreased, and the timing of the start of background activity in RF before S2 would be delayed. Third, a high correlation would also be observed between CNV peak time and the start time of RF activity before S2.

\section{Methods \\ Subjects}

Fifteen healthy young adults (8 men, 7 women) participated in this experiment. Mean (standard deviation (SD)) age, height, weight, foot length (FL), and auditory threshold were 22.7 (4.7) years, 166.9 (8.3) cm, 60.0 (8.8) kg, 24.4 (1.4) cm, and $28.0(4.6) \mathrm{dB}$, respectively. No subject had any history of neurological or orthopedic impairment. Informed consent was obtained from all subjects following an explanation of the experimental protocols, which were approved by the ethics committee at Kanazawa University (No. 946).

\section{Apparatus and data recording}

A force platform (FPA34; Electro Design, Nagareyama, Japan) was used to measure the center of pressure in the 
anteroposterior direction (CoPap). CoPap signals were sent simultaneously to one computer (PC9801BX2; NEC, Tokyo, Japan) to determine CoPap position online and to another computer for analysis offline. The former received CoPap data via an A/D converter (PIO9045; I/O-Data, Kanazawa, Japan) at $20 \mathrm{~Hz}$ with 12-bit resolution and could generate a buzzer sound when CoPap was within $\pm 1 \mathrm{~cm}$ of the position for the quiet standing (QS) posture. During QS, the frequency of body sway is below $5 \mathrm{~Hz}$; especially, the main frequency is below $1.5 \mathrm{~Hz}[29,30]$. Therefore, the $20-\mathrm{Hz}$ sampling frequency is commonly used in the studies on the postural sway [31]. CoPap position was calculated as the percentage distance from the heel in relation to FL (\%FL). The platform was fixed to a handmade table that was movable horizontally in an anteroposterior direction by a linear motion guide actuator (SKR4610A-0290-1-1001; THK, Tokyo, Japan) with a computer-controlled electric motor (SANMOTION model No. PB PBBR604; Sanyo Denki, Tokyo, Japan). The direction, velocity, and amplitude of platform movement were adjusted by the motor. S1 was an auditory stimulus delivered via earphones at a frequency of $2000 \mathrm{~Hz}, 35 \mathrm{~dB}$ above the threshold and lasting $50 \mathrm{~ms}$. S2 was a forward floor translation. Floor translation was detected by an accelerometer (AS-2GB; Kyowa, Tokyo, Japan) fixed to the platform.

The position of the body in the sagittal plane was recorded using the Position Sensor System (C5949; Hamamatsu Photonics, Hamamatsu, Japan). This system comprises a sensor head and light-emitting diode (LED) targets and emits analog outputs of the coordinates of the LED targets in two dimensions. The sensor head was placed $4 \mathrm{~m}$ from the left side of the subject. LED targets were placed over the platform and the following landmarks on the left side: vertebra prominens (C7); midpoint of the greater trochanter (hip); lateral condyle of the femur (knee); and lateral malleolus (ankle). The $\mathrm{x}$ - and $\mathrm{y}$ coordinates of LED targets were recorded at a $0.3-\mathrm{mm}$ resolution.

$\mathrm{Ag}-\mathrm{AgCl}$ cup electrodes (8-mm diameter) for recording EEG were placed on the scalp at $\mathrm{Fz}, \mathrm{Cz}$, and $\mathrm{Pz}$ in accordance with the international 10-20 system, and referenced to linked ear lobes. A ground electrode was placed at Fpz. Electrooculography (EOG) was recorded from a pair of electrodes placed above and below the right eye. To fix the eye position, subjects were instructed to gaze at a fixation point presented on an eye-trek facemounted display (FMD011F; Olympus, Tokyo, Japan). Surface electrodes (P-00-S; Ambu, Ballerup, Denmark) were used in bipolar derivation to record surface electromyography (EMG) of the following muscles on the right side: rectus abdominis (RA), erector spinae (ES), RF, biceps femoris (BF), TA, medial head of gastrocnemius (GcM), and soleus (Sol). For each muscle, electrodes were fixed after shaving and cleaning the skin with alcohol. The electrodes were aligned along the long axis of the muscle with an inter-electrode distance of about $3 \mathrm{~cm}$. Electrode input impedance was $<5 \mathrm{k} \Omega$. Signals from electrodes were amplified (EEG, $\times 40000$; EOG, $\times 4000$; EMG, $\times 4000$ ) and band-pass filtered (EEG, 0.05-100 Hz; EOG, 0.05-30 Hz; EMG, 5-500 Hz) using an amplifier (Biotop 6R12; NECSanei, Tokyo, Japan). In many CNV studies with 2-s inter stimulus interval, the high-pass filter around $0.05 \mathrm{~Hz}$ has been used [32-35].

For subsequent analyses, all electrical signals including CoPap, EEG, EOG, and EMG were sent to the computer for analysis (Dimension E521; Dell, Kawasaki, Japan) via an A/D converter (ADA16-32/2(CB)F; Contec, Osaka, Japan) at $1000 \mathrm{~Hz}$ with 16-bit resolution.

\section{Joint fixation of the ankle}

The outline of the method for ankle joint fixation is shown in Fig. 1. The lower legs and feet were fixed using aluminum frames and a wooden block mounted on the platform. While the subject maintained QS posture with the heels slightly touching the wooden block, the legs were secured with three horizontal bars of the frames, two from the front of the legs and another from the back, and two belts each for the left and right legs. The front bars had two wooden boards along with the long axis of the legs, for which the angle of inclination could be adjusted to the legs. Fixation of foot position was ensured by wrapping the ankle joint and wooden block together with another two belts for each foot. To avoid overly tight wrapping, a towel or sponge was placed between the legs and fixation tool. During these fixation processes, the buzzer sound was continually generated to indicate QS posture.

\section{Procedure}

All measurements were performed while the subject stood barefoot, with feet $10 \mathrm{~cm}$ apart and parallel on the force platform and the upper limbs crossed in front of the chest (Fig. 1). Mean CoPap position was initially measured for $10 \mathrm{~s}$ with the subject maintaining QS posture. The mean value of five trials was adopted as the QS position. Next, mean CoPap position during extreme backward leaning (EBL) was measured twice. Subjects gradually leaned backward from QS posture for approximately $5 \mathrm{~s}$, pivoting at the ankles, and then maintained this EBL posture for $3 \mathrm{~s}$. The more posterior mean CoPap position of two trials was adopted as the EBL mean position, and the posterior peak position of CoPap in the adopted trial was defined as the EBL peak position.

Velocity and amplitude of floor translation was set for each subject based on EBL mean and peak positions $[16,36]$. To begin, a 5 - or $10-\mathrm{cm}$ floor translation was applied at a velocity of $10 \mathrm{~cm} / \mathrm{s}$. If the posterior peak 


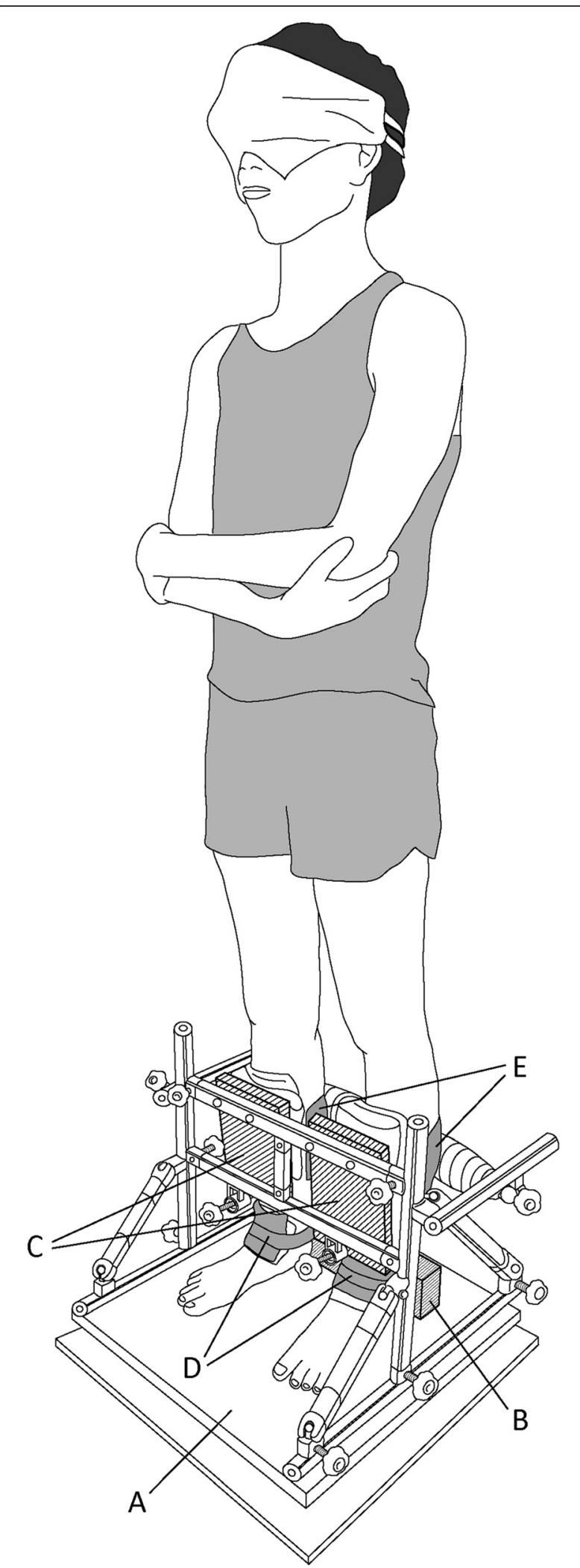

Fig. 1 Experimental setup. (A) Force platform, (B) wooden block, (C) wooden board, $(D)$ belt for the foot, $(E)$ belt for the leg of CoPap after translation at either amplitude was located between EBL mean position and EBL peak position, $10 \mathrm{~cm} / \mathrm{s}$ was adopted as the translation velocity. If not, velocity was reduced or increased until the posterior peak at either amplitude was located between these positions (change in $5-\mathrm{cm} / \mathrm{s}$ increments). Second, a linear regression line was drawn through the two coordinates of the floor translation amplitude $(5$ and $10 \mathrm{~cm}$ ) and the posterior peak of CoPap at each of the two floor translation amplitudes at the determined velocity. Based on this line, the translation amplitude at which the posterior peak would be located between the EBL mean position and EBL peak position was determined. Mean (SD) values for adopted translation velocity and amplitude were $20.0(5.0) \mathrm{cm} / \mathrm{s}$ and $7.3(2.3) \mathrm{cm}$, respectively.

The experimental session was carried out as follows. In both setting the translation intensity and in the experimental session, subjects maintained CoPap position within the QS position $\pm 1 \mathrm{~cm}$, as presented by a buzzer sound for at least $3 \mathrm{~s}$, until S2 onset. S1 was randomly presented 1-2 $\mathrm{s}$ after the experimenter stopped the buzzer sound, then $\mathrm{S} 2$ started $2 \mathrm{~s}$ after S1. Subjects were instructed to avoid changing the initial foot position in response to S2. A set of 20 trials was repeatedly performed twice for each condition (early- and latter-half sets). Trials were excluded if a change in foot position was observed or if CoPap deviated more than $\pm 1 \mathrm{~cm}$ from QS position before S2. Subjects were given a standing rest period of $30 \mathrm{~s}$ between trials and a seated rest period of 3 and $10 \mathrm{~min}$ between every ten trials and between fixation conditions, respectively.

\section{Data analyses}

All data analyses were performed using BIMUTAS II software (Kissei Comtec, Nagano, Japan). To evaluate the magnitude of backward disturbance in response to floor translation, the posterior peak of CoPap after S2 was identified in each trial and the distance from EBL mean position to this peak position was calculated. The mean value from all trials in each set was defined as the CoPap displaced position.

EEG, EMG, CoPap, and position sensor data from $500 \mathrm{~ms}$ before S1 to $3000 \mathrm{~ms}$ after S2 were averaged for each set. Trials with eye blinks or movement artifacts (voltage at EOG or any EEG electrode exceeding $\pm 100 \mu \mathrm{V}$ ) between $500 \mathrm{~ms}$ before S1 and S2 were excluded from averaging. At least 12 trials were included in the average for each set, as the minimum number of averagings in previous CNV studies [37]. For EEG, mean amplitude for the 500ms period before S1 was used as a baseline of averaging. Prior to averaging, EMG data were high-pass filtered at $40 \mathrm{~Hz}$ using a seventh-order Butterworth filter to exclude electrocardiographic and movement artifacts, then fullwave rectified. For position sensor data, waveforms of the 
$\mathrm{x}$ - and $\mathrm{y}$-coordinates were first smoothed by an 89-point moving average, corresponding to a $5-\mathrm{Hz}$ low-pass filter. Hip angle (knee - hip - C7), knee angle (ankle - knee hip), and ankle angle (inclination of ankle - knee from vertical line) were then calculated from the coordinates, using Excel 2010 software (Microsoft, Tokyo, Japan). Joint angles were calculated for every data point, and the waveform was then averaged.

In the averaged waveforms after S2, joint angle and EMG were analyzed. Movement angle of each joint was defined as the difference between maximal and minimal values after S2. EMG was analyzed only in the frontal postural muscles (RA, RF, and TA), since the direction of postural disturbance was backward only and burst activity just after S2 was observed mainly in these muscles. In order to smooth this averaged EMG waveforms, an 11-point moving average corresponding to a $40-\mathrm{Hz}$ lowpass filter was used with reference to the previous studies [3, 38]. The maximum peak after S2 for these muscles was identified, and peak amplitude and latency were measured relative to the baseline and S2, respectively.

For analysis in the period before S2, averaged EEG, EMG, and CoPap waveforms were smoothed by a 111point moving average, corresponding to a $4-\mathrm{Hz}$ low-pass filter. CNV peaked just before S2 and then changed positively in 12 of 15 subjects, and in the other 3 subjects, the negative potential was not clearly increased. Thus, the following analyses between S1 and S2 were performed for the 12 subjects. Mean amplitudes for every 100-ms period from $100 \mathrm{~ms}$ before S1 to S2 onset were then calculated. CNV analyses used averaged EEG waveforms recorded from $\mathrm{Cz}$, in which late $\mathrm{CNV}$ was maximal in all sets. CNV can be classified into early and late components [39]. The early component has been reported as the potential between 300 and $700 \mathrm{~ms}$ after $\mathrm{S} 1$, and the late component as the negative potential, which gradually increases toward S2 following the early component [40-42]. The periods from $700 \mathrm{~ms}$ after S1 to $\mathrm{S} 2$ were thus used for the analysis of mean amplitudes for every $100 \mathrm{~ms}$ of CNV, EMG, and CoPap. For the mean amplitude of CoPap, the difference from the mean amplitude for the 500-ms period before $\mathrm{S} 1$ was also calculated, since forward deviation was observed early after S1.

A maximal negative potential identified from $1400 \mathrm{~ms}$ after S1 to S2 was defined as the CNV peak, and the latency relative to $\mathrm{S} 2$ was calculated as $\mathrm{CNV}$ peak time. Changing patterns of frontal muscle activity and CoPap movement around the CNV peak were analyzed as follows [20]. The 500-ms period from 700 to $200 \mathrm{~ms}$ before the CNV peak was defined as the base period. For EMG, a continuous increase in preparation for S2 was identified as activation exceeding $2 \mathrm{SD}$ above the mean amplitude of the base period for $>50 \mathrm{~ms}$ until S2 and the minimum value of this activation was defined as the onset point. When a continuous increase of EMG was not observed, presence of a CoPap forward shift exceeding $2 \mathrm{SD}$ above the mean amplitude in the base period until S2 was checked. If such a CoPap forward shift was observed, the inflection point was identified based on the second-order differentiated waveform and the start of the transient increase in EMG activity just before the inflection of the CoPap shift was identified in the same manner as the start of the continuous increase. The time difference between the start of the increase in EMG and S2 was defined as the EMG start time before S2.

\section{Statistical analyses}

Shapiro-Wilk tests confirmed that all data satisfied assumptions of normal distribution. Two-way repeatedmeasures analysis of variance (ANOVA) was used to assess the main effects and interaction of condition (nofixation, fixation) and set (early half, latter half) on analysis parameters after S2, mean amplitude of CNV, EMG, and CoPap for every 100-ms period between S1 and S2, and $\mathrm{CNV}$ peak time and peak amplitude. When a significant interaction was shown, paired $t$ tests were used for post hoc comparison to investigate differences within each factor. For EMG peak latency after S2, to assess whether effects of condition (no-fixation, fixation) and set (early half, latter half) differed among muscles (RA, RF, TA), threeway ANOVA was performed first, then the post hoc Games-Howell test was used to further investigate differences among muscles. To investigate the effects of joint fixation, a paired $t$ test was used to compare each parameter across the latter half under the no-fixation condition and the early half under the fixation condition. To investigate changing patterns of CNV and EMG waveforms in the period corresponding to the late $\mathrm{CNV}$, with the mean amplitude for every 100-ms period, the difference between the period of $700-800 \mathrm{~ms}$ after S1 and other periods was evaluated using Dunnett's test. A one-sample $t$ test was used to assess whether the CoPap displaced position and CoPap mean amplitude for every 100-ms period between S1 and S2 differed significantly from the EBL mean position and mean amplitude for the 500-ms period before S1, respectively. Pearson's correlation was used to assess the relationship between CNV peak time and EMG start time before S2. The alpha level was set at $p<0.05$. All statistical analyses were performed using IBM SPSS Statistics 19 (IBM Japan, Tokyo, Japan).

\section{Results}

The statistical results of ANOVA are shown in Table 1 . The results of main effects and post hoc tests are described in the text with corresponding $p$ values.

Figure 2 shows mean CoPap displaced position after S2. The mean displaced position was significantly forward in the latter half compared to the early half $(p<0.001)$, 
Table 1 Results of analysis of variance (ANOVA)

\begin{tabular}{|c|c|c|c|}
\hline Dependent variables & $\begin{array}{l}\text { Significant interaction } \\
\text { or main factor }\end{array}$ & $F$ values & Significance \\
\hline \multicolumn{4}{|l|}{ Two-way ANOVA } \\
\hline CoPap displaced position & Set & $F_{1,14}=22.0$ & $p<0.001$ \\
\hline Hip joint movement angle & Set & $F_{1,14}=5.7$ & $p<0.05$ \\
\hline Knee joint movement angle & Interaction & $F_{1,14}=6.5$ & $p<0.05$ \\
\hline \multirow[t]{2}{*}{ Ankle joint movement angle } & Condition & $F_{1,14}=19.6$ & $p<0.01$ \\
\hline & Set & $F_{1,14}=14.0$ & $p<0.01$ \\
\hline Peak amplitude of RA after S2 & Interaction & $F_{1,14}=5.0$ & $p<0.05$ \\
\hline \multirow[t]{2}{*}{ Peak amplitude of RF after S2 } & Condition & $F_{1,14}=7.2$ & $p<0.05$ \\
\hline & Set & $F_{1,14}=23.0$ & $p<0.001$ \\
\hline \multirow[t]{2}{*}{ Peak amplitude of TA after S2 } & Condition & $F_{1,14}=118.0$ & $p<0.001$ \\
\hline & Set & $F_{1,14}=103.6$ & $p<0.001$ \\
\hline CNV peak amplitude & Nothing & $F_{1,11}<1.1$ & N.S. \\
\hline CNV peak time & Condition & $F_{1,11}=9.8$ & $p<0.05$ \\
\hline Mean amplitude of CNV from 700 to 800 ms after S1 & Condition & $F_{1,11}=4.9$ & $p<0.05$ \\
\hline \multirow[t]{2}{*}{ Mean amplitude of CNV from 800 to 900 ms after S1 } & Condition & $F_{1,11}=5.2$ & $p<0.05$ \\
\hline & Set & $F_{1,11}=5.4$ & $p<0.05$ \\
\hline Mean amplitude of CNV from 900 to 1500 ms after S1 & Set & $F_{1,11}=5.7$ & $p<0.05$ \\
\hline Mean amplitude of CNV from 1600 ms after S1 to S2 & Nothing & $F_{1,11}=2.8$ & N.S. \\
\hline Mean amplitude of RA from 700 ms after S1 to S2 & Nothing & $F_{1,11}=3.3$ & N.S. \\
\hline Mean amplitude of RF from 700 ms after S1 to S2 & Nothing & $F_{1,11}=4.6$ & N.S. \\
\hline Mean amplitude TA from 700 to 1500 ms after S1 & Nothing & $F_{1,11}<4.5$ & N.S. \\
\hline Mean amplitude of TA from 1600 ms after S1 to S2 & Interaction & $F_{1,11}>5.0$ & $p<0.05$ \\
\hline Mean amplitude of CoPap from 700 ms after S1 to S2 & Condition & $F_{1,11}>8.0$ & $p<0.05$ \\
\hline \multicolumn{4}{|l|}{ Tree-way ANOVA } \\
\hline Peak latency of frontal postural muscles after S2 & $\begin{array}{l}\text { Interaction between } \\
\text { condition and muscle }\end{array}$ & $F_{2,42}=6.8$ & $p<0.01$ \\
\hline
\end{tabular}

If a significant interaction was found, the statistical value of that interaction alone was described. If significant main factors were found, but no interactions, only the statistical values of the main factors were described

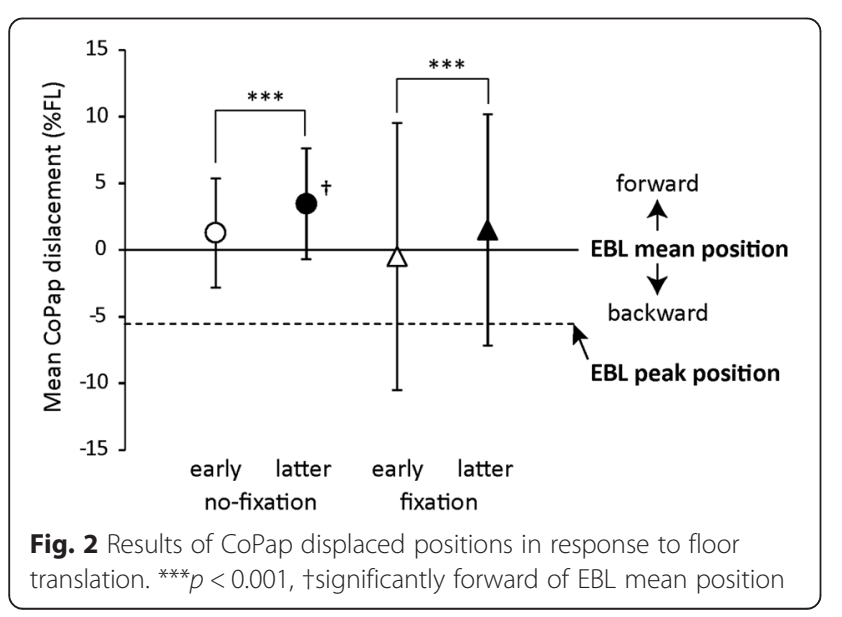

regardless of fixation condition. Under the no-fixation condition, position in the latter half was significantly forward of the EBL mean position $\left(t_{14}=3.2, p<0.01\right)$.

Figure 3 shows joint movement angle after S2. In the no-fixation condition, movement angle was significantly smaller in the latter half than in the early half for all three joints $(p<0.05)$. Movement angles of the ankle and knee were significantly smaller in the early half under the fixation condition than in the early and latter half under the no-fixation condition $(p<0.05)$. In the fixation condition, movement angles of the ankle and hip were significantly smaller in the latter half than in the early half $(p<0.05)$, whereas that of the knee showed no significant change.

Figure 4 shows burst peak amplitude and latency of postural muscle after S2. In the no-fixation condition, burst peaks occurred in order of TA, RF, and RA, with significant differences among muscles $(p<0.01)$, regardless of 


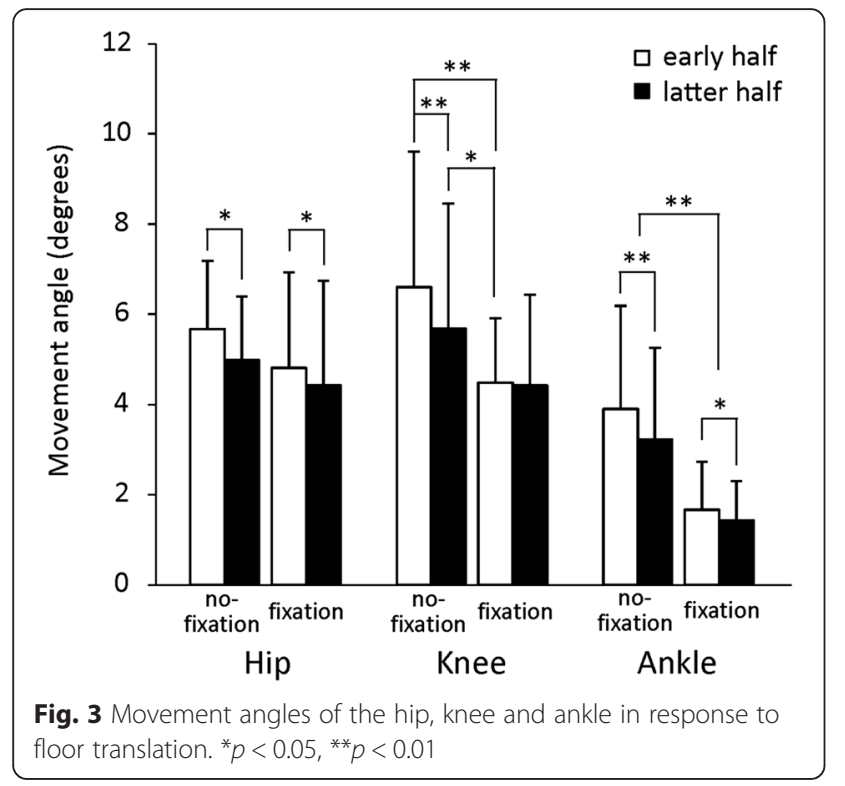

set. In the fixation condition, burst peak latencies of TA and RF were significantly earlier than that of RA $(p<0.05)$, and no significant difference was found between TA and $\mathrm{RF}$, regardless of set. Compared to the no-fixation condition, peak latency under fixation was significantly delayed in TA $(p<0.05)$ and shortened in RA $(p<0.01)$. Peak amplitudes of all three muscles were significantly decreased in the latter half than in the early half under the no-fixation condition $(p<0.01)$. With fixation, the amplitude increased significantly in RF $(p<0.05)$ and decreased in TA $(p<0.05)$, regardless of set. In the latter half under fixation, amplitudes of TA and RF decreased significantly compared to the early half $(p<0.001)$. For RA, peak amplitude in the early half was significantly smaller in the fixation condition than in the no-fixation $(p<0.05)$.
Late CNV peaked just before S2 and then changed positively in 12 of 15 subjects. In the other three subjects, the negative potential was not clearly increased, and the following analysis between S1 and S2 was thus performed for the 12 subjects. Mean amplitudes for every $100 \mathrm{~ms}$ between S1 and S2 of CNV, EMG, and CoPap are shown in Fig. 5. CNV mean amplitude in the following periods was significantly larger than the $700-800$ ms period: from 1300 to $1700 \mathrm{~ms}$ in the early half and from 1700 to $1900 \mathrm{~ms}$ in the latter half under no-fixation; and from 1400 to $2000 \mathrm{~ms}$ in the latter half under fixation $(p<0.05)$. In the period from 800 to $1500 \mathrm{~ms}$, CNV mean amplitude was significantly smaller in the latter half than in the early half $(p<0.05)$. In the period from 700 to $900 \mathrm{~ms}$, $\mathrm{CNV}$ mean amplitude was significantly smaller under fixation than under no-fixation $(p<0.05)$. No significant differences were seen across all four sets in CNV peak amplitude (mean across all sets: 9.6 (4.1) V). CNV peak time was significantly later in the fixation condition than in the no-fixation condition $(p<0.001)$, regardless of set (means between sets in the no-fixation and fixation conditions: -280.5 (163.1) $\mathrm{ms}$ and -171.8 (148.4) $\mathrm{ms}$, respectively).

In the S1-S2 period (Fig. 5), CoPap mean position gradually deviated forward until S2 under the nofixation condition. A significant forward displacement relative to the mean CoPap position before S1 was found in all periods after $600 \mathrm{~ms}$ in both halves under the no-fixation condition $\left(t_{11}>2.3, p<0.05\right)$. Mean CoPap positions in all periods after $700 \mathrm{~ms}$ were significantly more forward under no-fixation than under fixation, regardless of set $(p<0.05)$. Mean TA amplitude tended to increase gradually until S2 under the no-fixation condition. A significant increase

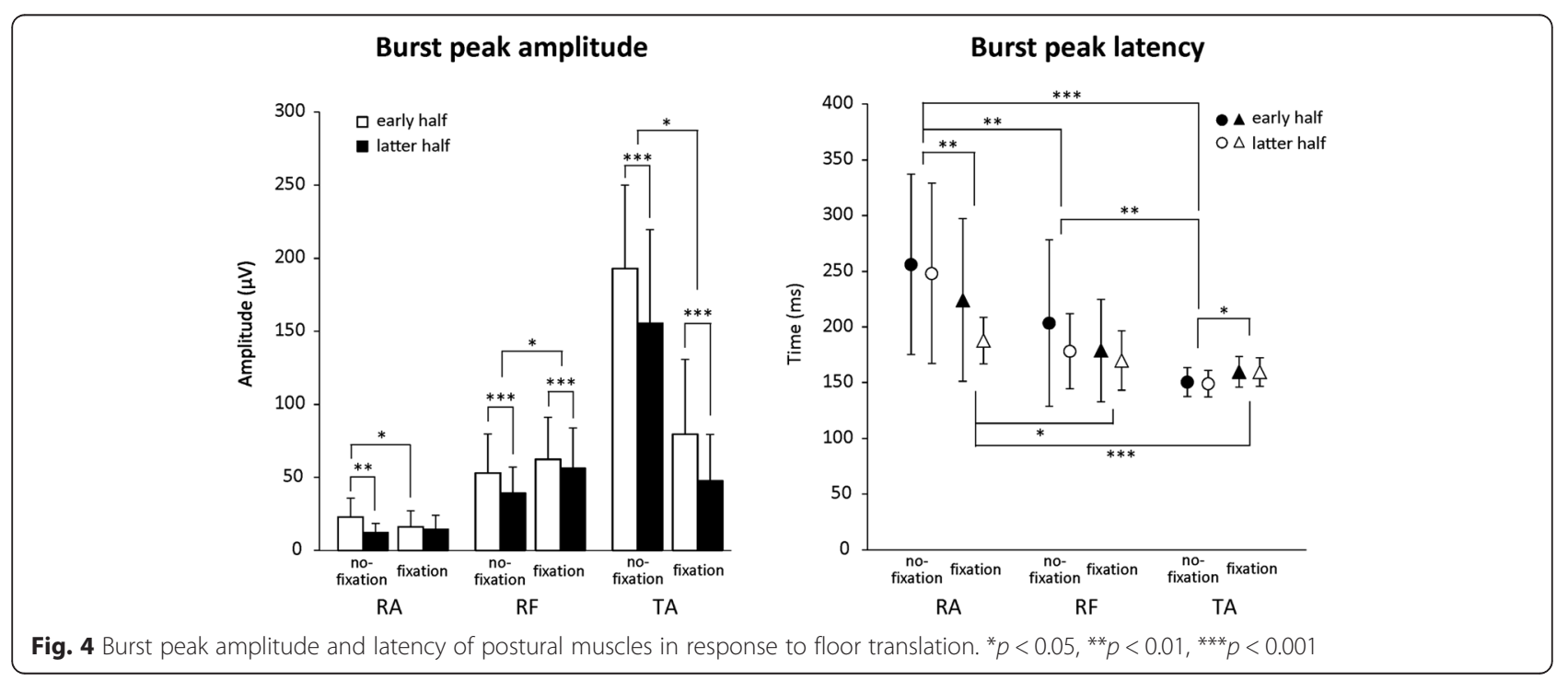




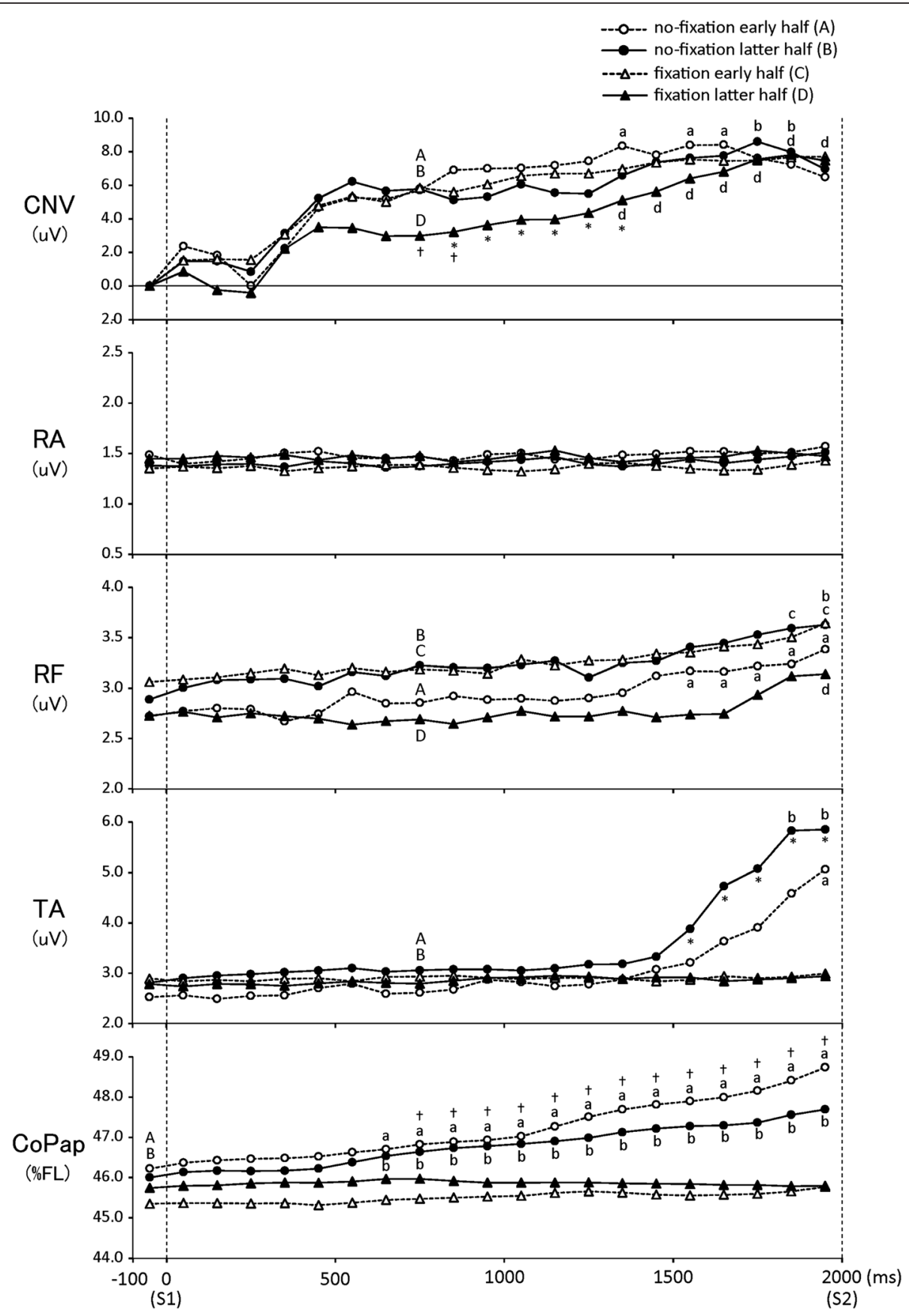

Fig. 5 Mean amplitude for every 100-ms period of CNV, EMG, and CoPap between S1 and S2. *Significant difference between early-and latter-half sets $(p<0.05)$. tSignificant difference between fixation conditions $(p<0.05)$. Lowercase letters indicate a significant increase compared with corresponding capital letters $(p<0.05)$

relative to the $700-800 \mathrm{~ms}$ period was found in the 1900-2000 ms period for the early half and in the periods after $1800 \mathrm{~ms}$ for the latter half $(p<0.05)$. Mean TA amplitudes in the periods after 1600 ms were significantly larger in the latter half than in the early half under the no-fixation condition. For RF, mean amplitudes tended to increase until S2 in all four sets. In particular, in the latter half under the fixation, the increase in RF mean amplitude tended to start just before $\mathrm{S} 2$. Under the nofixation condition, a significant increase relative to the 700-800 ms period was found in the periods after $1500 \mathrm{~ms}$ for the early half and in the 1900-2000 ms period for the latter half. Under fixation, a significant increase relative to the $700-800 \mathrm{~ms}$ period was found in the periods after $1800 \mathrm{~ms}$ for the early half and in the 1900$2000 \mathrm{~ms}$ period for the latter half $(p<0.05)$. For RA, no 
tendency toward activation increase was observed until S2 and no significant differences were found between conditions and sets in every period.

Around the CNV peak point, the following EMG activations were found: a continuous increase from around $\mathrm{CNV}$ peak to S2 (no-fixation: early half 10; latter 6, fixation: early 10; latter 9) or a transient increase followed by forward displacement of CoPap (no-fixation: early 1, latter 5 ; fixation: early 3, latter 1). The EMG start time before S2 was similar across all 4 sets (mean -344.4 (195.2) ms). A slight increase in EMG slightly preceded the CNV peak (mean $118 \mathrm{~ms}$ ), with no significant differences between them. Under nofixation, a significant correlation between $\mathrm{CNV}$ peak time and EMG start time was found in TA $(r=0.84)$ and RF $(0.87)$ in the early half, and in TA (0.81) in the latter half (all $p<0.05$, Fig. 6). Under fixation, a significant correlation with CNV peak time was found in the RA $(0.91)$ in the early half and RF $(0.67)$ in the latter half (both $p<0.05)$.

\section{Discussion}

Before adaptation in the no-fixation condition, CoPap was displaced to a position near EBL (Fig. 2), which is an index of the posterior limit of stability. During forward floor translation, the main joint for postural control is the ankle and TA activates as a focused postural muscle [3, 16]. In the present study, TA activated earliest and largest under the no-fixation condition (Fig. 4), suggesting that the focused postural muscle was the TA. CoPap displacement and TA activation decreased adaptively with trial repetition (Figs. 2 and 4).

Under the fixation condition, the peak latency of TA became longer and almost the same as the RF peak latency. The peak amplitude of TA decreased markedly, while that of RF increased significantly. The peak latency of RA became slightly shorter with fixation, but was still longer than those of RF or TA (Fig. 4). These results suggest that unification below the knee by ankle fixation would result in

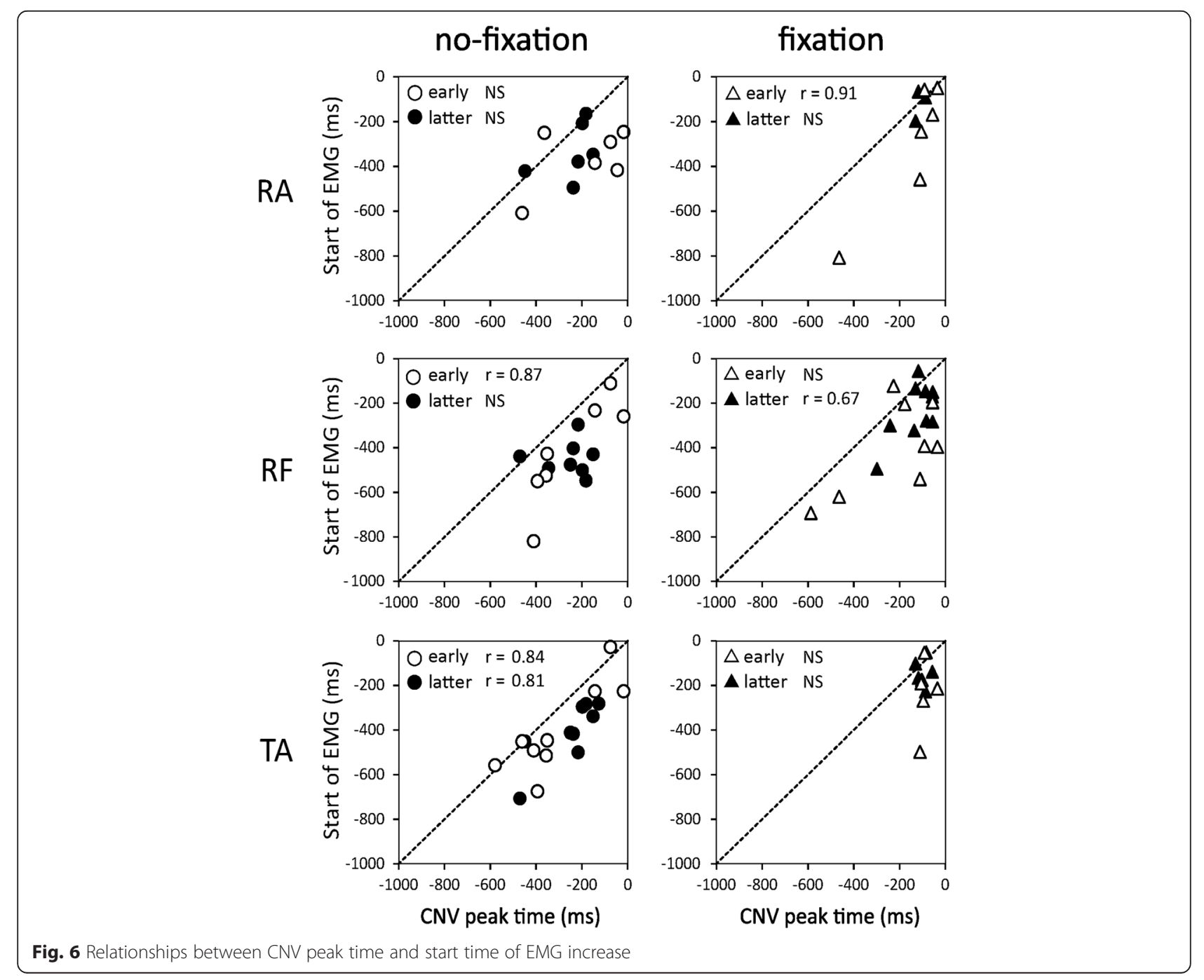


backward disturbance around the knee joint and a change in the main activation muscle for postural control to RF. The later latency of RA is attributable to the characteristics of viscoelastic body $[4,43]$. Movement angle of the knee joint became slightly smaller (Fig. 3), which was attributed to the increase in RF activation. In addition, CoPap displacement, activation of TA and RF, and movement angles of ankle and hip joints decreased with postural adaptation under the fixation condition (Figs. 2, 3, and 4). These results suggest adaptation to the new postural control strategy. No adaptive changes in peak latency of all postural muscles were seen (Fig. 4), indicating that activation order of postural muscles did not change with postural adaptation. Thus, after adaptation with ankle fixation, the main activation muscle for postural control should still be RF, and activation would become more effective according to adaptation.

The CNV amplitude increased extremely until $800 \mathrm{~ms}$ from S1 before adaptation, regardless of ankle fixation, and increased slightly after that point. According to postural adaptation, the $\mathrm{CNV}$ amplitude tended to decrease during the period of 800-1500 ms after S1, but the peak amplitude did not show differences with ankle fixation or adaptation (Fig. 5). Thus, after adaptation, CNV was small until $1500 \mathrm{~ms}$ after S1 and then increased to the peak point, which was remarkable in the fixation condition. Late CNV reflects the motor preparation process and anticipatory attention directed to S2 [22, 23]. The amplitude just before S2 reportedly increases with a more difficult task or larger attention directed to S2 [20, 44]. In the present study, although the timing of peak attentional allocation became closer to $\mathrm{S} 2$ onset by ankle fixation, the amount of attentional allocation just before S2 would be equal among fixation conditions or adaptation states. Moreover, the timing of the start of allocation would become later with adaptation, particularly under fixation conditions. In previous studies using the $\mathrm{S} 1-\mathrm{S} 2$ task, in which $\mathrm{S} 1$ is a simple warning signal and $\mathrm{S} 2$ is a finger response or arm movement, no early CNV increase was found [21, 25]. On the other hand, in the S1-S2 task in which S2 was a transient floor translation, CNV increased early as in the present study, before adaptation [16]. However, with the considerable trial repetition ( $>90$ trials), the negative potential of early CNV seemed to decrease [28, 45]. The decrease in early CNV amplitude after postural adaptation would indicate that according to postural adaptation, attention should not increase beforehand, especially in cases where attention was directed only to the knee joint because of ankle fixation.

In the S1-S2 interval, without ankle fixation, CoPap shifted early to a forward position and postural muscles activated relatively early for RF and just before S2 for TA. With ankle fixation, no forward shifts in CoPap or increases in TA were found, but RF activation increased toward S2
(Fig. 5). CoPap shift would represent the control of standing position to moderate postural disturbance [20]. The large background activity of postural muscles would be related to the increase in stiffness against the disturbance, leading to the above-mentioned early burst activation to S2. The inclination of the whole body pivoting at the ankles is a postural movement pattern to effectively translate the center of gravity [46]. Due to the immobility of the ankle joint under fixation, a postural strategy with increased postural muscle stiffness, but without a shift in standing position, would be selected, and the main activation muscle should be RF. Furthermore, after adaptation with ankle fixation, RF background activity increased rapidly from $400 \mathrm{~ms}$ before S2 (Fig. 5). This changing pattern of RF from before to after adaptation was similar to that of CNV. These results suggest that immediately after the ankle fixation, attention and/or muscle activity to the postural perturbation would anticipatorily be heightened in relation to the changes of somatosensory information by fixation or short-term memory. Furthermore, according to postural adaptation under the fixation condition, even when the timing of onset for the increase in RF stiffness becomes just before S2, postural disturbance can be moderated, resulting in a later start in direction of attention to S2.

The late CNV peak just before S2 has been suggested to correspond to a peak in anticipatory attention and/or onset of attentional shift to objects other than S2, such as sensory information and output of motor commands [20, 24]. This peak time correlated positively with the start time for the increase in muscle activation before S2 after adaptation for TA under no-fixation and RF under fixation (Fig. 6). With adaptation, although attention would be focused on sensory information processing related to the TA in many subjects under no-fixation conditions, the target of attention would change to RF with fixation.

\section{Conclusion}

With joint fixation of the ankle, as the main joint in the postural control, the main activation muscle changed from TA to RF during forward floor translation. The early component of CNV became smaller with adaptation, especially under fixation conditions, suggesting a decrease in the need for anticipatory attention from the early stage. Correspondingly, the timing of the increase in RF stiffness may be delayed. After adaptation, a significant correlation between the timing of CNV peak and increased muscle activation just before S2 was found in TA with no-fixation and in RF with fixation, suggesting that under ankle fixation, the target of attention would change to RF with postural adaptation.

\section{Abbreviations}

ANOVA, analysis of variance; $B F$, biceps femoris; $C 7$, vertebra prominens; $C N V$, contingent negative variation; CoPap, center of foot pressure in the anteroposterior direction; EBL, extreme backward leaning; EEG, 
electroencephalogram; EMG, electromyography; EOG, electrooculography; ES, erector spinae; FL, foot length; GcM, gastrocnemius; LED, light-emitting diode; QS, quiet standing; RA, rectus abdominis; RF, rectus femoris; S1, warning stimulus; S2, imperative stimulus; SD, standard deviation; Sol, soleus; TA, tibialis anterior

\section{Acknowledgements}

This work was supported by Grant-in-Aid for Scientific Research (B) (23300238) from the Japan Society for the Promotion of Science.

\section{Authors' contributions}

The contribution of each author is as follows: LV and KF developed the idea of this study, planed the method, directed the experiments, and interpreted the results. NK and MI interpreted the results and drafted the manuscript with LV and KF. HT contributed to the experiments and data analysis with LV and KF. CY corrected whole sentences of the manuscript. All authors read and approved the final manuscript.

\section{Competing interests}

The authors declare that they have no competing interests.

\section{Author details}

'Department of Orthopaedic Surgery, Graduate School of Medical Science, Kanazawa University, 13-1 Takara-machi, Kanazawa 920-8641, Japan. ${ }^{2}$ Department of Sports and Health, Kanazawa Gakuin University, 10 Sue-machi, Kanazawa 920-1392, Japan. ${ }^{3}$ Department of Rehabilitation, Japan Health Care College, 6-17-3 Megumino-nishi, Eniwa 061-1373, Japan. ${ }^{4}$ Department of Rehabilitation Science, Osaka Health Science University, 1-9-27 Tenma, Kita-ku, Osaka 530-0043, Japan. ${ }^{5}$ Department of Physical Therapy, Hokkaido Bunkyo University, 5-196-1 Kogane-chuo, Eniwa 061-1449, Japan.

\section{Received: 16 April 2016 Accepted: 14 July 2016}

\section{Published online: 25 July 2016}

\section{References}

1. Forssberg $\mathrm{H}$, Nashner LM. Ontogenetic development of postural control in man: adaptation to altered support and visual conditions during stance. J Neurosci. 1982;2:545-52.

2. Fujiwara $\mathrm{K}$, Ikegami $\mathrm{H}$. The characteristics of postural response in upright stance to the floor vibration. Jap J Phys Educ. 1984;29:251-61 [In Japanese with English Abstract].

3. Horak FB, Nashner LM. Central programming of postural movements: adaptation to altered support-surface configurations. J Neurophysiol. 1986; 55:1369-81.

4. Buchanan JJ, Horak FB. Emergence of postural patterns as a function of vision and translation frequency. J Neurophysiol. 1999;81:2325-39.

5. Horak FB, Moore SP. The effect of prior leaning on human postural responses. Gait Posture. 1993;1:203-10.

6. Hughes MA, Schenkman ML, Chandler JM, Studenski SA. Postural responses to platform perturbation: kinematics and electromyography. Clin Biomech. 1995;10:318-22.

7. Bernstein NA. The coordination and regulation of movements. London: Oxford Pergamon Press; 1967.

8. Runge CF, Shupert CL, Horak FB, Zajac FE. Postural strategies defined by joint torques. Gait Posture. 1999;10:161-70.

9. Manchester D, Woollacott MH, Zederbauer-Hylton N, Marin O. Visual, vestibular and somatosensory contributions to balance control in the older adult. J Gerontol. 1989:44:118-27.

10. Studenski S, Duncan PW, Chandler J. Postural responses and effector factors in persons with unexplained falls: results and methodologic issues. J Am Geriatr Soc. 1991;39:229-34.

11. Mouchnino L, Mille ML, Cincera M, Bardot A, Delarque A, Pedotti A, Massion J. Postural reorganization of weight-shifting in below-knee amputees during leg raising. Exp Brain Res. 1998;121:205-14.

12. Mouchnino L, Gueguen N, Blanchard C, Boulay C, Gimet G, Viton JM, Franceschi JP, Delarque A. Sensori-motor adaptation to knee osteoarthritis during stepping-down before and after total knee replacement. BMC Musculoskelet Disord. 2005;6:21.

13. Bhatt T, Wening JD, Pai YC. Adaptive control of gait stability in reducing slip-related backward loss of balance. Exp Brain Res. 2006;170:61-73.
14. Martelli D, Vashista V, Micera S, Agrawal S. Direction-dependent adaptation of dynamic gait stability following waist-pull perturbations. IEEE Trans Neural Syst Rehabil Eng. 2015. doi:10.1109/TNSRE.2015.2500100.

15. Fujiwara K, Kiyota N, Maekawa M, Prokopenko SV, Vasilyevna AM. Postural control during transient floor translation while standing with the leg and trunk fixed. Neurosci Lett. 2015:594:93-8.

16. Fujiwara K, Maekawa M, Kiyota N, Yaguchi C. Adaptation changes in dynamic postural control and contingent negative variation during backward disturbance by transient floor translation in the elderly. J Physiol Anthropol. 2012;24:12.

17. Fujiwara K, Maeda K, Irei M, Mammadova A, Kiyota N. Changes in eventrelated potentials associated with postural adaptation during floor oscillation. Neuroscience. 2012;213:122-32.

18. Jacobs JV, Fujiwara K, Tomita H, Furune N, Kunita K, Horak FB. Changes in the activity of the cerebral cortex relate to postural response modification when warned of a perturbation. Clin Neurophysiol. 2008;119:1431-42.

19. Fujiwara K, Tomita H, Maeda K, Kunita K. Effects of neck flexion on contingent negative variation and anticipatory postural control during arm movement while standing. J Electromyogr Kinesiol. 2009;19:113-21.

20. Fujiwara K, Kiyota N, Maeda K. Contingent negative variation and activation of postural preparation before postural perturbation by backward floor translation at different initial standing positions. Neurosci Lett. 2011;490:135-9.

21. Maeda K, Fujiwara K. Effects of preparatory period on anticipatory postural control and contingent negative variation associated with rapid arm movement in standing posture. Gait Posture. 2007;25:78-85.

22. Rohrbaugh JW, Syndulko K, Lindsley DB. Brain wave components of the contingent negative variation in humans. Science. 1976;191:1055-7.

23. Brunia CH, van Boxtel GJ. Wait and see. Int J Psychophysiol. 2001;43:59-75.

24. Macar F, Vidal F. Time processing reflected by EEG surface Laplacians. Exp Brain Res. 2002;145:403-6.

25. Pfeuty M, Ragot R, Pouthas $V$. When time is up: CNV time course differentiates the roles of the hemispheres in the discrimination of short tone durations. Exp Brain Res. 2003;151:372-9.

26. Maekawa M, Fujiwara K, Kiyota N, Yaguchi C. Adaptation changes in dynamic postural control and contingent negative variation during repeated transient forward translation in the elderly. J Physiol Anthropol. 2013;32:24.

27. Karayanidis F, Jamadar SD. Event-related potentials reveal multiple components of proactive and reactive control in task switching. In: Grange JA, Houghton G, editors. Task Switching and Cognitive Control. New York: Oxford University Press; 2014. p. 200-36.

28. Rose $M$, Verleger $R$, Wascher E. ERP correlates of associative learning. Psychophysiology. 2001;38:440-50.

29. Njiokiktjien C, de Rijke W. The recording of Romberg' test and its application in neurology. Agressologie. 1972;13:1-7.

30. Miyoshi T, Shirato M, Hiwatari S. Correlation between the directions of body sway. Equilibrium Res. 1978;37:107-12 [In Japanese with English Abstract].

31. Fujiwara $\mathrm{K}$, Ikegami $\mathrm{H}$. Chronological change in frequency component of body sway in upright stance. Jpn J Hum Posture. 1984;4:81-8 [In Japanese with English Abstract].

32. Ikeda A, Shibasaki H, Kaji R, Terada K, Nagamine T, Honda M, Kimura J. Dissociation between contingent negative variation (CNV) and Bereitschaftspotential (BP) in patients with parkinsonism. Electroencephalogr Clin Neurophysiol. 1997;102:142-51.

33. Yazawa S, Shibasaki H, Ikeda A, Terada K, Nagamine T, Honda M. Cortical mechanism underlying externally cued gait initiation studied by contingent negative variation. Electroencephalogr Clin Neurophysiol. 1997;105:390-9.

34. Jonkman LM, Lansbergen M, Stauder JE. Developmental differences in behavioral and event-related brain responses associated with response preparation and inhibition in a go/nogo task. Psychophysiology. 2003;40:752-61.

35. Sadeghi M, Talebian S, Olyaei GR, Attarbashi MB. Preparatory brain activity and anticipatory postural adjustments accompanied by externally cued weighted-rapid arm rise task in non-specific chronic low back pain patients and healthy subjects. Springerplus. 2016;5:674.

36. Kiyota T, Fujiwara K, Toyama H, Kiyota N, Kunita K, Maeda K, Katayama M. Determination of disturbance parameters of forward floor translation for balance training to prevent falling. Health Behav Sci. 2009;8:9-16.

37. Tecce JJ. Contingent negative variation (CNV) and psychological processes in man. Psychol Bull. 1972;77:73-108.

38. Cordo PJ, Nashner LM. Properties of postural adjustments associated with rapid arm movements. J Neurophysiol. 1982;47:287-302. 
39. Klorman $\mathrm{R}$, Bentsen $\mathrm{E}$. Effects of warning-signal duration on the early and late components of the congingent negative variation. Biol Psychol. 1975;3:263-75.

40. Yoshida K, lizuka T. Contingent negative variation elicited before jaw and tongue movements. J Oral Rehabil. 2005:32:871-9.

41. Lai C, Ikeda A, Terada K, Nagamine T, Honda M, Xu X, Yoshimura N, Howng S, Barrett G, Shibasaki H. Event-related potentials associated with judgment: comparison of S1- and S2-choice conditions in a contingent negative variation (CNV) paradigm. J Clin Neurophysiol. 1997;14:394-405.

42. Zappoli R, Versari A, Paganini M, Arnetoli G, Roma V, Battaglia A, Porcù S. Age differences in contingent negative variation activity of healthy young adults and presenile subjects. Ital J Neurol Sci. 1988;9:219-30.

43. van Dieën JH, Toussaint HM, Sta C, Hol J. Viscoelasticity of the individual spine. Clin Biomech (Bristol, Avon). 1994;9:61-3.

44. Wright MJ, Geffen GM, Geffen LB. Event related potentials during covert orientation of visual attention: effects of cue validity and directionality. Bio Psychol. 1995;41:183-202.

45. Smith BA, Jacobs JV, Horak FB. Effects of amplitude cueing on postural responses and preparatory cortical activity of people with Parkinson disease. J Neurol Phys Ther. 2014;38:207-15.

46. Crenna P, Frigo C, Massion J, Pedotti A. Forward and backward axial synergies in man. Exp Brain Res. 1987;65:538-48.

\section{Submit your next manuscript to BioMed Central} and we will help you at every step:

- We accept pre-submission inquiries

- Our selector tool helps you to find the most relevant journal

- We provide round the clock customer support

- Convenient online submission

- Thorough peer review

- Inclusion in PubMed and all major indexing services

- Maximum visibility for your research

Submit your manuscript at www.biomedcentral.com/submit

) Biomed Central 